\title{
Voltage Stability of Short Transmission Line Equipped with a Thyristor Controlled Series Capacitor
}

\author{
Prechanon Kumkratug \\ Division of Electrical Engineering, Faculty of Engineering at Si Racha, \\ Kasetsart University, 199 M.6, Tungsukhla, Si Racha, Chonburi, 20230, Thailand
}

Received 2012-03-18, Revised 2012-09-06; Accepted 2012-11-08

\begin{abstract}
It is becoming increasingly important to fully utilize the existing transmission system assets due to environmental legislation, rights-of-way issues, costs of construction and deregulation policies that introduced in recent years. The Thyristor Controlled Series Capacitor (TCSC) has been proposed for the better control power flow and dynamic performance. The exact short transmission line model consists of the resistance and reactance. Most of previous researches studies voltage stability performance of the TCSC in SMIB System with neglecting the resistance of the line. Thus the fully capability of the TCSC on voltage stability improvement of power system may not be applied. The consideration of the resistance causes in the difficulty of deriving the mathematical model. This study investigates the effect of the TCSC on voltage stability of the power system with consideration the exact short transmission line mode. The concept of twoport network is applied to simplify the mathematical model of the power system. The proposed method is tested on sample system and compared on various cases. The first swing of rotor angle curve of the faulted system without resistance is obviously higher than that of with resistance whereas the second swing of the faulted system without resistance is slightly less than that of with resistance. The system with a TCSC can improve voltage stability of power system. It was found from this study that the TCSC and resistance of the line can improve first swing of rotor angle. However, the resistance of the line provides the negative effect on second swing of rotor angle. The simulation results indicate that for practical short line, the resistance is very import parameters for evaluating voltage stability of power system.
\end{abstract}

Keywords: Thyristor Controlled Series Capacitor (TCSC), Flexible AC Transmission System (FACTS), Critical Clearing Time (CCT), Single Machine Infinite Bus (SMIB)

\section{INTRODUCTION}

Power system stability is classified as rotor angle stability and voltage stability. Voltage stability is stability in power systems which are heavily loaded, distubeanced or have a shortage of reactive power. Nowadays, the demand of electricity has dramatically increased and a modern power system becomes a complex network of transmission lines interconnecting the generating stations to the major loads points in the overall power system in order to support the high demand of consumers. It is becoming increasingly important to fully utilize the existing transmission system assets due to environmental legislation, rights-of- way issues and costs of construction and deregulation policies that introduced in recent years. A number of Flexible AC Transmission System (FACTS) controllers, based on the rapid development of power electronics technology, have been proposed for better utilization of the existing transmission systems (Hassan et al., 2010; Omar et al., 2010; Osuwa and Igwiro, 2010; Kumar et al., 2012; Zarate-Minano et al., 2010).

The evaluation of the Power-Votage (P-V) curve of the power system is one of the most important research areas for power engineers because it indicates the maximum power load. If the load is increased beyond the maximu value, the voltage will be collapsed and then the system is considered as unstable. 


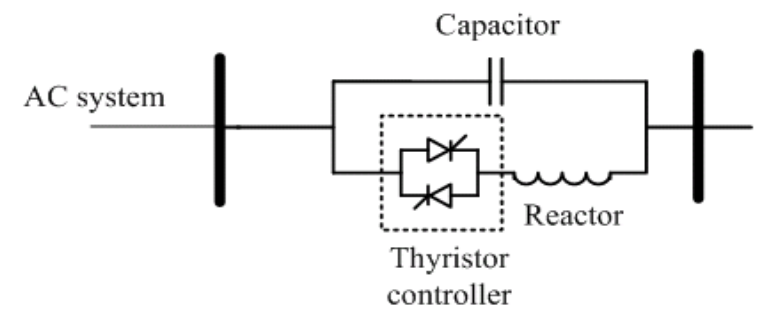

Fig. 1. Schematic diagram of TCSC

The Thyristor Controlled Series Capacitor (TCSC) is the series FACTS devices. It consists of the capacitor bank reactor bank and thyristor as shown in Fig. 1. The thyristors control the reactance or susceptance that dictates the power flow through a line. The TCSC can be applied for improving stability of power system (Kumkratug, 2010).

The evaluation of Critical Clearing Time (CCT) of power system is one of the most important research areas for power engineers because it indicates the robustness of the faulted power system. The rotor angle of the synchronous generator determines the stability of power system. Although the stability of the synchronous machine is used to represent the stability of the power system, all of the power system components such as transmission line and transformer affect the stability of the power system.

The transmission line is one of the most important parts in power system components. Most of the fault occurs at the transmission line. The transmission line is generally divided into three major categories; short, medium and long model whose distance are about $80 \mathrm{~km}$, above $80-250 \mathrm{~km}$ and above $250 \mathrm{~km}$, respectively. Many previous researches used simple transmission line model by neglecting its resistance or capacitance. To fully utilization the existing system, the exact transmission line should be further investigated.

This study will investigate the capability of the TCSC on voltage stability of the SMIB system with the exact short transmission line model. The concept of twoport network is applied to simplify the mathematical model of the power system. The sample system consisting the practical short transmission line is used to investigate in this study. The proposed method is tested on various cases.

\section{MATERIALS AND METHODS}

\subsection{Mathematical Model}

Figure 2a shows the single line diagram of power system consisting of a short transmission line seried with a
Thyristor Controlled Series Capacitor (TCSC). The voltage at generator bus $\left(\mathrm{V}_{\mathrm{S}}\right)$ is considered as constant value. The short transmission line model is represented by a impledant $Z$. The load is represented by the active $\left(P_{R}\right)$ and reactive power $\left(\mathrm{Q}_{\mathrm{R}}\right)$.

The ABCD constants of short transmission line model in two ports network are given in Eq. 1-4:

$$
\begin{aligned}
& \mathrm{A}_{1}=1 \\
& \mathrm{~B}_{1}=\mathrm{Z} \\
& \mathrm{C}_{1}=0 \\
& \mathrm{D}_{1}=1
\end{aligned}
$$

The ABCD constants of a TCSC in two ports network are given in Eq. 5-8:

$$
\begin{aligned}
& \mathrm{A}_{\mathrm{TCSC}}=1 \\
& \mathrm{~B}_{\mathrm{TCSC}}=-\mathrm{j} \mathrm{X}_{\mathrm{TCSC}} \\
& \mathrm{C}_{\mathrm{TCSC}}=0 \\
& \mathrm{D}_{\mathrm{TCSC}}=1
\end{aligned}
$$

With the series combination of a transmission line and TCSC in two ports network as shown in Fig. 2b, a successive two ports networks is shown in Fig. $\mathbf{2 c}$ and its constant parameters are given in Eq. 9-12:

$$
\begin{aligned}
& \mathrm{A}_{\text {eq }}=\mathrm{A}_{1} \mathrm{~A}_{\mathrm{TCSC}}+\mathrm{B}_{1} \mathrm{C}_{\mathrm{TCSC}} \\
& \mathrm{B}_{\mathrm{eq}}=\mathrm{A}_{1} \mathrm{~B}_{\mathrm{TCSC}}+\mathrm{B}_{1} \mathrm{D}_{\mathrm{TCSC}} \\
& \mathrm{C}_{\mathrm{eq}}=\mathrm{A}_{\mathrm{TCSC}} \mathrm{C}_{1}+\mathrm{C}_{\mathrm{TCSC}} \mathrm{D}_{1} \\
& \mathrm{D}_{\mathrm{eq}}=\mathrm{B}_{\mathrm{TCSC}} \mathrm{C}_{1}+\mathrm{D}_{1} \mathrm{D}_{\mathrm{TCSC}}
\end{aligned}
$$

Then the active and reactive power load are given in Eq. 13-14:

$$
P_{R}=\frac{V_{R} V_{S}}{B_{e q}} \cos \left(\theta_{B}-\delta\right)-\frac{A_{e q} V_{R}^{2}}{B_{e q}} \cos \left(\theta_{B}-\theta_{A}\right)
$$

And:

$$
\mathrm{Q}_{\mathrm{R}}=\frac{\mathrm{V}_{\mathrm{R}} \mathrm{V}_{\mathrm{S}}}{\mathrm{B}_{\mathrm{eq}}} \sin \left(\theta_{\mathrm{B}}-\delta\right)-\frac{\mathrm{A}_{\mathrm{eq}} \mathrm{V}_{\mathrm{R}}^{2}}{\mathrm{~B}_{\mathrm{eq}}} \cos \left(\theta_{\mathrm{B}}-\theta_{\mathrm{A}}\right)
$$




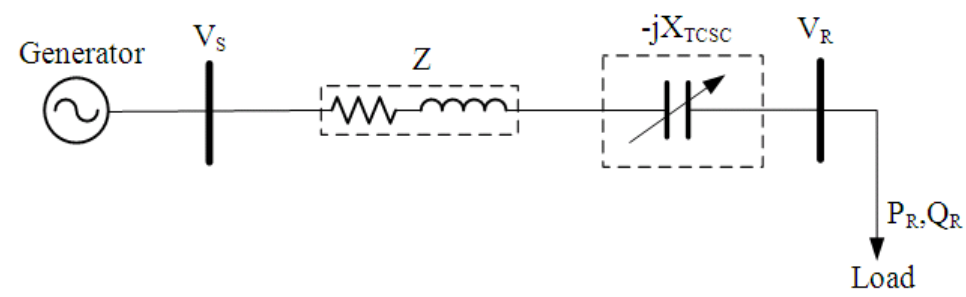

(a)

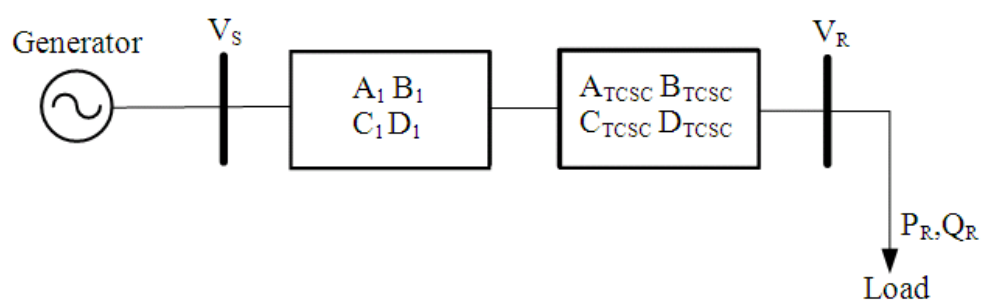

(b)

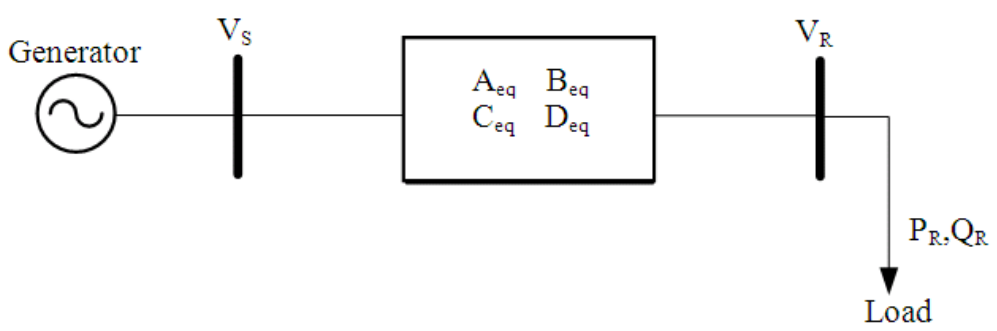

(c)

Fig. 2. Single machine infinite bus system with a TCSC (a) schematic diagram (b) equivalent circuit (c) two ports network diagram (d) a successive two-ports network

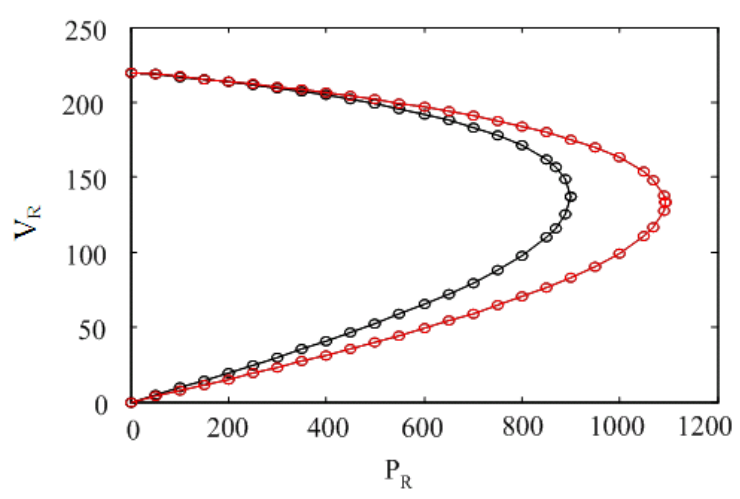

Fig. 3. P-V curve of the system without and with a TCSC for unity power factor

The objective of this study is to evaluate the voltage at load bus $\left(\mathrm{V}_{\mathrm{R}}\right)$ with various cases of load. This study applies the Newton-Raphson method to iteratively solve the nonlinear Eq. 13 and 14 and given by Eq. 15:

$$
\left[\begin{array}{c}
\Delta \mathrm{P}_{\mathrm{R}} \\
\Delta \mathrm{Q}_{\mathrm{R}}
\end{array}\right]=\left[\begin{array}{l}
\frac{\partial \mathrm{P}_{\mathrm{R}}}{\partial \mathrm{Q}_{\mathrm{R}}} \frac{\partial \mathrm{P}_{\mathrm{R}}}{\partial \mathrm{V}_{\mathrm{R}}} \\
\frac{\partial \mathrm{Q}_{\mathrm{R}}}{\partial \delta} \frac{\partial \mathrm{Q}_{\mathrm{R}}}{\partial \mathrm{V}_{\mathrm{R}}}
\end{array}\right]\left[\begin{array}{c}
\Delta \delta \\
\Delta \mathrm{V}
\end{array}\right]
$$

\section{RESULTS}

The proposed method is tested on the sample system consider the diagram of sample system is shown in Fig. 2. The system supplies power which is transferred through a $40 \mathrm{~km}$ transmission line to the load. The system voltage at the generator bus is $220 \mathrm{kV}$.

It is considered that the variable capacitive reactance of a TCSC is operated at $50 \%$ of the line reactance. 


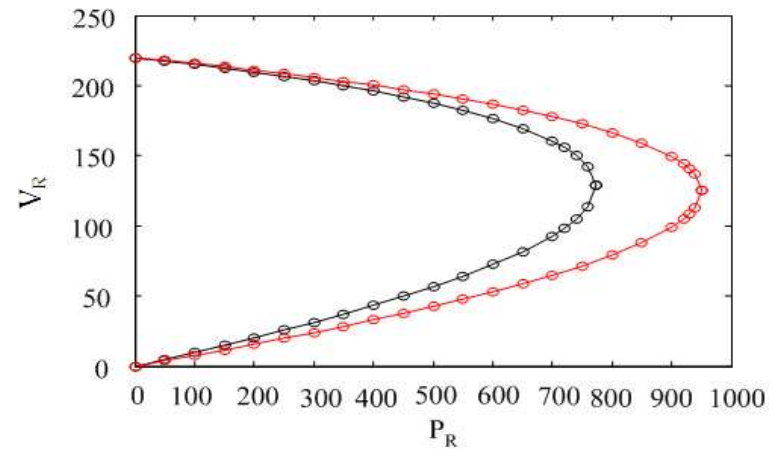

Fig. 4. P-V curve of the system without and with a TCSC for $\phi$ $=0.2$

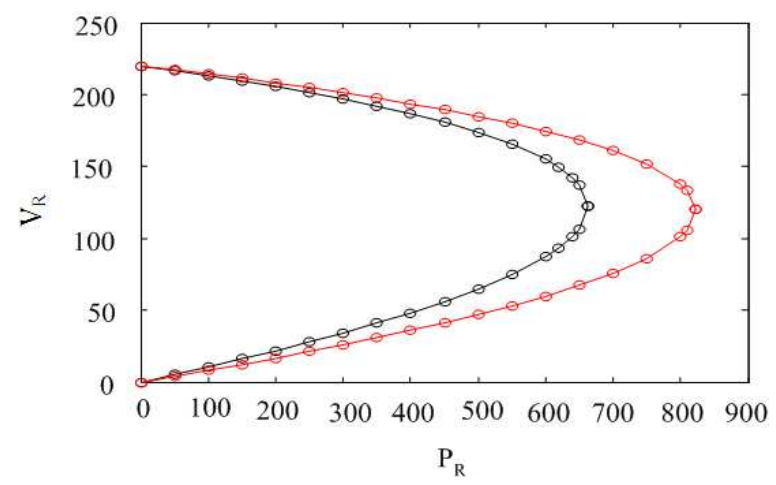

Fig. 5. P-V curve of the system without and with a TCSC for $\phi$ $=0.4$

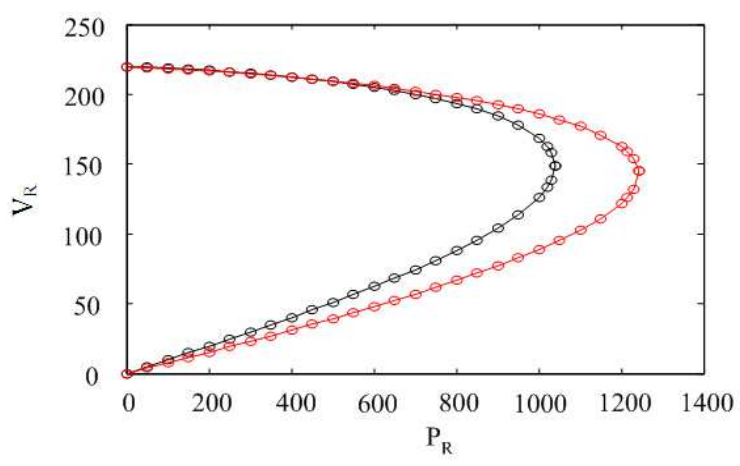

Fig. 6. P-V curve of the system without and with a TCSC for $\tan \phi=-0.2$

The comparison of the Power-Voltage (P-V) curve of the system with and without a TCSC for various power factors is shown in Fig. 3-7. Table 1 summarizes the critical point $\left(\mathrm{P}_{\mathrm{R}}^{\mathrm{cr}}, \mathrm{V}_{\mathrm{R}}^{\mathrm{cr}}\right)$ of the system without and with a TCSC for various power factors.

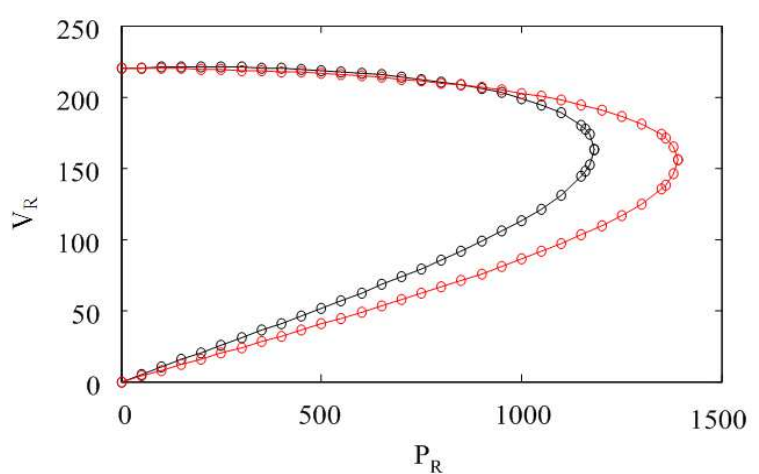

Fig. 7. P-V curve of the system without and with a TCSC for $\phi$ $=-0.4$

Table 1. The maximum and minimum rotor angle of the system with a TCSC and various parameters of the short transmission line

\begin{tabular}{|c|c|c|c|c|c|}
\hline \multirow[b]{2}{*}{ Case } & \multirow[b]{2}{*}{$\tan \phi$} & \multicolumn{2}{|c|}{ Without TCSC } & \multicolumn{2}{|c|}{ With a TCSC } \\
\hline & & $\begin{array}{l}P_{R}^{c r} \\
(W)\end{array}$ & $\begin{array}{l}\mathrm{V}_{\mathrm{R}}^{\mathrm{cr}} \\
(\mathrm{kV})\end{array}$ & $\begin{array}{l}\mathrm{P}_{\mathrm{R}}^{\mathrm{cr}} \\
(\mathrm{W})\end{array}$ & $\begin{array}{l}\mathrm{V}_{\mathrm{R}}^{\mathrm{cr}} \\
(\mathrm{kV})\end{array}$ \\
\hline 1 & 0.4 & 663.2 & 122.3 & 823.2 & 120.1 \\
\hline 2 & 0.2 & 773.3 & 128.7 & 949.9 & 125.3 \\
\hline 3 & 0.0 & 900.2 & 137.4 & 1092.3 & 133.3 \\
\hline 4 & -0.2 & 1038.8 & 149.1 & 1241.9 & 145.5 \\
\hline 5 & -0.4 & 1181.1 & 163.2 & 1390.8 & 155.8 \\
\hline
\end{tabular}

\section{DISCUSSION}

It can be seen from the Fig. 3-7 and the Table that a TCSC can improve voltage stability of the system. Without a TCSC and unity power, the critical point $\left(\mathrm{P}_{\mathrm{R}}^{\mathrm{cr}}, \mathrm{V}_{\mathrm{R}}^{\mathrm{cr}}\right.$ ) is at $900.2 \mathrm{~W}$ and $137.4 \mathrm{kV}$. In this case, it indicates that the maximumum power load is around 900 W. However, with a TCSC, the maxmum power load is increased to $1092 \mathrm{~W}$. This study investigates the effect of power factor on the critical point. With the lagging power factor, the crtical point point is reduced whereas with the leading power factor, the crtical point point is increased. With $\tan \phi=-0.4$ and with a TCSC, the maximum power is reduced to $823 \mathrm{~W}$ whereas $\tan \phi=0.4$ and with a TCSC, the maximum power is increased to $1390 \mathrm{~W}$.

\section{CONCLUSION}

This study investigated the effects of the Thyristor Controlled Series Capacitor (TCSC) on the voltage stability improvement of the Single Machine Infinite Bus 
(SMIB) system with the consideration of the exact short transmission line model. The mathematical model was systematically derived by using the concept of the twoport network. This concept can help us to obtain mathematical model of the system in the simpler way.

The presented methods were tested and compared on various cases. It was found from the simulation results that the TCSC improve the voltage stability performance. The leading power factor and a TCSC operated in capacitive mode can improve voltage stability.

\section{REFERENCES}

1. Kumar, K.R., S. Palaniswami and K.S. Kumar, 2012. Artificial neural network based rotor capacitive reactance control for energy efficient wound rotor induction motor. J. Comput. Sci., 8: 1085-1091. DOI: $10.3844 /$ jcssp.2012.1085.1091

2. Hassan, L.H., M. Moghavvemi and H.A.F. Mohamed, 2010. Power system oscillations damping using unified power flow controllerbased stabilizer. Am. J. Applied Sci., 7: 13931395. DOI: 10.3844 /ajassp.2010.1393.1395
3. Omar, R., N.A. Rahim and M. Sulaiman, 2010. New control technique applied in dynamic voltage restorer for voltage sag mitigation. Am. J. Eng. Applied Sci., 3: 42-48. DOI: 10.3844/ajeassp.2010.42.48

4. Osuwa, J.C. and E.C. Igwiro, 2010. Uninterruptible power supply using solar rechargeable battery. Phys. Int., 1: 77-82. DOI: 10.3844/pisp.2010.77.82

5. Kumkratug, P., $3297 . \quad$ DOI: 10.3844/ajassp.2011.355.358

6. Zarate-Minano, R., T.V. Custsem, F. Milano and A.J. Conejo, 2010. Sexuring transient stability using time domain simulations within an optimal power flow. IEEE Trans. Power Syst., 5: 243-253. 